\title{
HIDATIK KIST
}

\section{HYDATID CYST}

\author{
Muhammet Reha Çelik, Hakkı Ulutaş, Akın Kuzucu \\ İnönü Üniversitesi Tıp Fakültesi, Göğüs Cerrahisi Anabilim Dalı, Malatya, Türkiye \\ e-posta: rehacelik@yahoo.com,drhakkiulutas@yahoo.com, akinkuzucu@yahoo.com \\ doi:10.5152/tcb.2012.18
}

\section{Özet}

Hidatik kist hastalığının etkeni cestod grubuna ait bir yassı solucan olan E. granulosus'dur. E. granulosus çok geniş bir coğrafi dağılım gösterir, ancak, koyun yetiştiriciliğinin yaygın olduğu bölgelerde yoğunlaşmıştır. En sık karaciğer ve akciğerleri tutar. Akciğer tutulumu genç yaş grubunda daha sık olarak görülür. Hastaların çoğu asemptomatik olmasına karşın, kist rüptüre olarak veya çevre dokulara bası oluşturarak semptomatik duruma gelebilir. Radyolojik olarak, soliter veya multiple, yuvarlak veya oval düzgün sınırlı kitle lezyonu şeklinde görülür. Rüptüre hidatik kistler değişik radyolojik bulgular gösterebilir. Hidatik kist tedavisinde bugün, parankim koruyucu cerrahi güvenli ve etkili bir ilk basamak tedavi olarak kabul edilmektedir. Postoperatif dönemde, kemoterapi nüksleri engellemek için kullanılabilir.

Anahtar kelimeler: Hidatik kist, akciğer

Hidatik kist hastalığı dünyada geniş coğrafi yayııım gösteren zoonozlardan biridir. Bu hastalığa bir yassı solucan olan Echinococcus granulosus'un metacestod evresindeki larvası neden olur. Cestoidea sınıfına dahil bir tenya olan Echinococcus'ların dört türü tanımlanmıştır. İnsanda en sık infestasyona sebep olan tür Echinococcus granulosus'dur (1). Insanlara, yaşam siklusunda yer alan hayvanlar yoluyla bulaşır. Hayvancılığın, özellikle koyun yetiştiriciliğinin yaygın olduğu Akdeniz, Doğu Avrupa, Afrika, Güney Amerika, Orta Doğu, Avusturalya, Yeni Zelanda ve Çin gibi bölgelerde sık görülür $(2,3)$. E. multilokularis daha nadir görülen alveoler echinococcosis'e neden olur. Arctic bölge, Asya'nın bazı bölgeleri ve batı-orta Avrupa gibi daha soğuk bölgelerde görülür (1-4). Primer yerleşim yeri karaciğerdir. $E$. vogeli ve $E$. oli-

\begin{abstract}
Hydatid cyst is caused by a small cestode tapeworm $E$. granulosus. E. granulosus has a worldwide distribution and is accumulated in sheep-raising areas. The liver and lungs are the most frequently involved organs. Pulmonary disease appears to be more common in younger individuals. Although most patients are asymptomatic, may develop symptoms related to cyst rupture or compression of the surrounding structures. The cyst is characteristically seen as a solitary or multiple, round or oval mass that has well-defined borders on imaging. Cystic rupture may appear as different radiological signs. Lung-preserving surgical procedures are the currently effective and safe "first line" management. Chemotherapy in the postoperative period can be given for preventing recurrences.
\end{abstract}

Key words: Hydatid cyst, lung

garthus Güney Amerika'da endemik olarak polikistik echinococcosis'e neden olurlar ve klinik önemleri sınırlıdır $(1,4)$.

\section{YAŞAM SIKLUSU}

E. granulosus yaşam siklusunu tamamlayabilmek için iki konağa gereksinim duyar. Erişkin formun bulunduğu köpek ve diğer yırtıcı etoburlar ana konak, yumurtadan larva formuna dönüştüğü koyun, keçi gibi otobur canlılar ara konağı oluşturur (1). E. multilocularis yaşam siklusunda ise tilki ve kurt gibi hayvanlar ana konak, kemirgenler ise ara konak olarak bulunur. İnsan tesadüfi bir arakonaktır (1). Larval formun insanda gelişimi ile aslında insan, siklusun tamamlanamadığı bir son ("dead-end") konaktır (5). 
Hastalık fekal-oral yol ile bulaşır. Ana konaktaki tenyanın yumurtaları dışkı ile atıır. Bu dışkı ile kontamine su ve gıdalar ara konaklar tarafından alınır. Ara konağın barsağında yumurtalar safra asitleri ve sindirim enzimleri ile açılır ve ortaya çıkan larvalar barsak mukozasına tutunur. Barsak mukozasında mezenterik dolaşıma katılan parazitler portal sistem yolu ile karaciğere ulaşır. Larvalar $25-30 \mu$ çapındadır. Çoğu, $30 \mu$ çapındaki karaciğer sinüzoidlerini geçemez. Bu nedenle kist hidatik en sık karaciğerde gelişir. Sinüzoidleri geçen larva hepatik ven, vena cava inferior, sağ kalp, pulmoner arterler yolu ile akciğere ulaşır. Akciğerde kapillerin çapı 8$\mu^{\prime}$ a kadar düşer. Akciğerlere ulaşan larvalar akciğer kapillerlerine takılıp akciğerlerde gelişimlerini tamamlarlar. Akciğerler kist hidatik'in ikinci sıklıkta görüldüğü organdır. Parazit akciğere transdiyafragmatik yol, lenfatik yol ve portokaval anastomozlar yoluyla da gelebilir.

Larva yerleştiği organda kistik metacestod formuna dönüşür. Büyüyen kistin çevresinde endotel hücreleri, eozinofiller ve dev hücreleri içeren, fibroblast ve kapillerden zengin fibröz tabaka oluşur (perikistik tabaka). Kist duvarı ise endokist ve egzokist olmak üzere iki tabakadan oluşmuştur. Mukopolisakkarit yapısında koruyucu dış tabaka egzokist, kız veziküllerin ve skolexlerin doğduğu fertil iç tabaka endokist olarak adlandırılır. Kistin içinde kaya suyu olarak adlandırılan berrak, steril ancak antijenik yapıda bir sıvı bulunur.

İnsanda gelişen hidatik kistler genellikle tektir ve primer kist olarak adlandırıı. Primer kist duvarının rüptürü sonucu kız veziküllerin ve skolekslerin, komşuluk veya kan yolu ile çevre dokulara ve uzak organlara taşınması, sekonder kistlerin oluşmasına neden olur.

\section{KLINIK BELIRTi}

Kist oluşumunun başlangıç dönemi genellikle asemptomatiktir ve genellikle $5 \mathrm{~cm}$. çapa ulaşıncaya kadar herhangi bir belirti vermezler (6). Belirtisi olmayan kistler daha çok rutin muayeneler sırasında, bir cerrahi girişim sırasında veya otopside saptanır (6). Belirtiler komşu organlara bası ile veya komplikasyonların gelişmesi ile ortaya çıkar. Pediyatrik yaş grubunda hidatik kistler immün cevabın tam gelişmemiş olması, akciğer parankiminin elastikiyetinin ve solunum kapasitesinin erişkinlere göre daha fazla olması nedeniyle bulgu vermeksizin dev boyutlara ulaşabilirler $(\geq 10 \mathrm{~cm})$ ve daha sonra semptomatik hale gelebilirler (7). Bu tip kistler daha çok bronşiyal ve/veya plevral irritasyona bağlı olarak göğüs ağrısı ve öksürüğe ve parankime yaptığı basıya bağlı olarak dispneye neden olurlar (8). Rüptüre hidatik kistlerde klinik tablo rüptürün yönüne göre değişir. Eğer kist bronşiyal sisteme rüptüre olursa kistik SIVI ve membran expectorasyonu, hemoptizi, pürülan balgam ve ateş gibi enfekte kist bulguları görülebilir. Büyük kistlerde bronşiyal rüptür asfiksiyle sonuçlanabilir. Eğer kist plevral boşluğa rüptüre olursa pnömotoraks, ampiyem, pyopnömotoraks gibi daha ciddi bir klinik tabloya neden olabilir (9).

\section{TANI}

Hidatik kist tanısı, kistlerin çeşitli görüntüleme yöntemleri ile gösterilmesi ile konulur. Tanı serolojik testler ile doğrulanabilir. Olguların \%60'ında soliter, \%20-50'sinde birden çok unilateral veya bilateral lezyon görülür (10). PA akciğer grafilerinde kistler homojen, yuvarlak veya oval, iyi sınırlı ve normal akciğer dokusu ile çevrili lezyonlar şeklinde görülürler (Resim 1). Eğer kist rüptüre olmuş ise kistik lezyonda spesifik bulgular ortaya çıkabilir. Buna karşın, bazen lezyon komşuluğunda konsalidasyon gelişir ve inflamatuvar reaksiyon, lezyonun net bir şekilde değerlendirilmesini engeller. Rüptüre lezyonda hava-sıvı seviyesi, menisküs belirtisi, cumbo belirtisi, nilüfer belirtisi, kavite içinde kitle veya membran görünümü düz grafilerde veya bilgisayarlı göğüs tomografisinde saptanabilen önemli bulgulardır $(1,10,11)$ (Resim 2). BT ve manyetik rezonans görüntülemede tekerlek belirtisi, "serpent" belirtisi, "spin-whirl" belirtisi, kist duvarı belirtisi, halka oluşum belirtisi, halo belirtisi, ters hilal belirtisi gibi belirtiler de tanımlanmıştır $(11,12)$ (Resim 3,4).

Akciğer tutulumunda serolojik testler yüksek yalan-

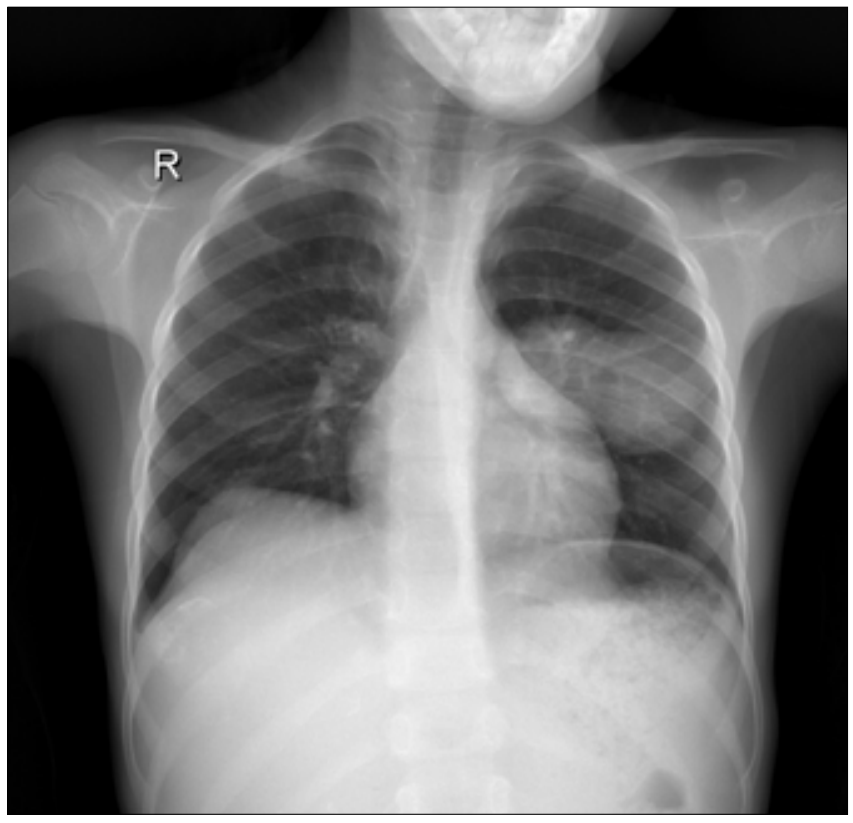

Resim 1. Dört yaşında kız çocuğu. Sol akciğerde iki adet düzgün sınırlı homojen kistik kitle lezyonu mevcut 
Cı pozitiflik ve yalancı negatiflik gösterdikleri için rutin kullanıma girmemiştir. Casoni deri testi ve Weinberg kompleman fiksasyon testleri günümüzde çok kullanımayan testlerdir. Dolaşımdaki antikorların saptanması E. granulosus antijenlerinin saptanmasına göre daha sensitiftir. ELISA, indirect hemagütinasyon antibody assay, latex aglütinaston testi, ve immünoblot test en yaygın kullanılan immünolojik metodlardır. İmmünolojik tanı yöntemleri sadece primer tanı amacıyla değil,

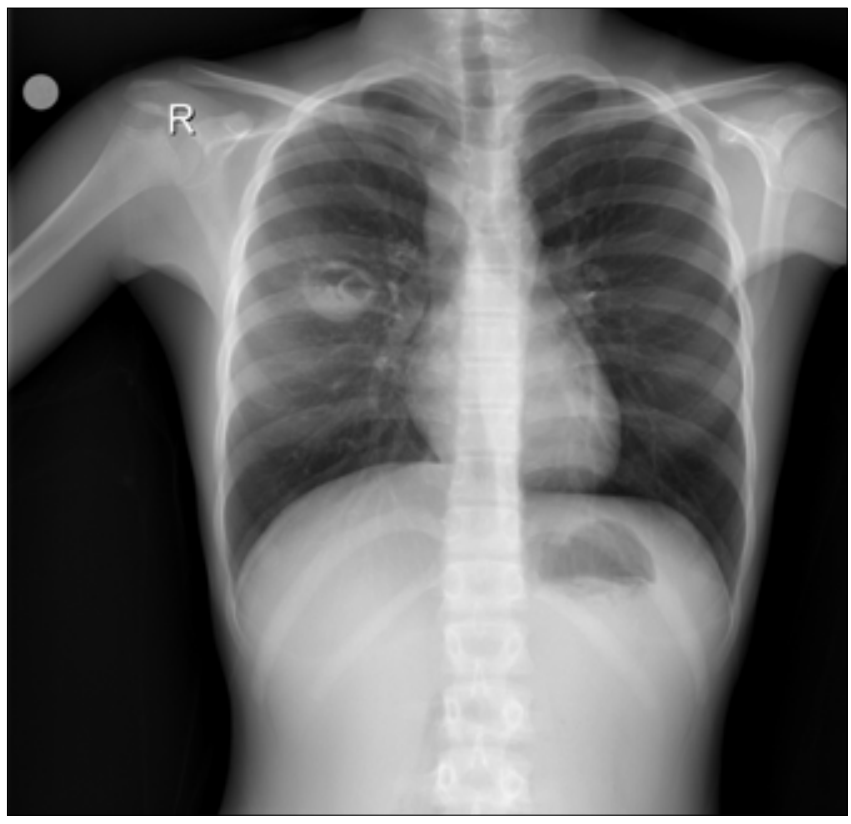

Resim 2. On üç yaşında kız çocuğu. PA akciğer grafisinde sağda düzgün sınırlı kaviter lezyon ve kavite içinde kistik membran görülüyor cerrahi veya medikal tedavi sonrası takip amacıyla da kullanılır (5).

\section{TEDAVi}

Hidatik kistin temel tedavi yöntemi cerrahidir. Çoğunlukla parazitik materyalin cerrahi olarak ortadan kaldırıması yeterlidir. Bu nedenle cerrahi tedavide mümkün olan en fazla miktarda akciğer dokusunun korunması prensibiyle hareket edilir. Akciğer parankiminde lezyonun çevresinde değişik evrelerde kronik konjesyon, hemoraji, bronkopnömoni ve intertisyel pnömoni bulunur (13). Bu tip inflamatuar değişiklikler kistin çıkarılması ile resorbe olur. Anatomik rezeksiyonları içeren daha radikal cerrahi girişimler ancak bu değişikliklerin irreverzible olduğu kabul edildiğinde bir tedavi seçeneği olarak düşünülür. Tüm yaş gruplarını içeren pekçok seride bildirilen anatomik rezeksiyon oranı \%0-10 arasında değişmektedir $(9,14,15)$. Yapılan bazı çalışmalarda bu oran pediyatrik yaş grubu için biraz daha yüksek bulunmuştur. Bu çalışmalarda, otörler bildirilen yüksek rezeksiyon oranlarını serilerindeki dev kistlerin ve komplike kistlerin fazlalığı ile açıklamışlardır (16-19). Ancak bugün pekçok otör, bu tip olgularda da konservatif yaklaşımların başarı oranınının yüksek olduğu savunmakta ve öncelikle parankim koruyucu cerrahi yöntemlerini önermektedir (20-22). Özellikle pediyatrik yaş grubunda akciğerin iyileşme ve reekspansiyon kapasitesinin daha iyi olması parankim koruyucu cerrahide başarı şansını arttırır (20).

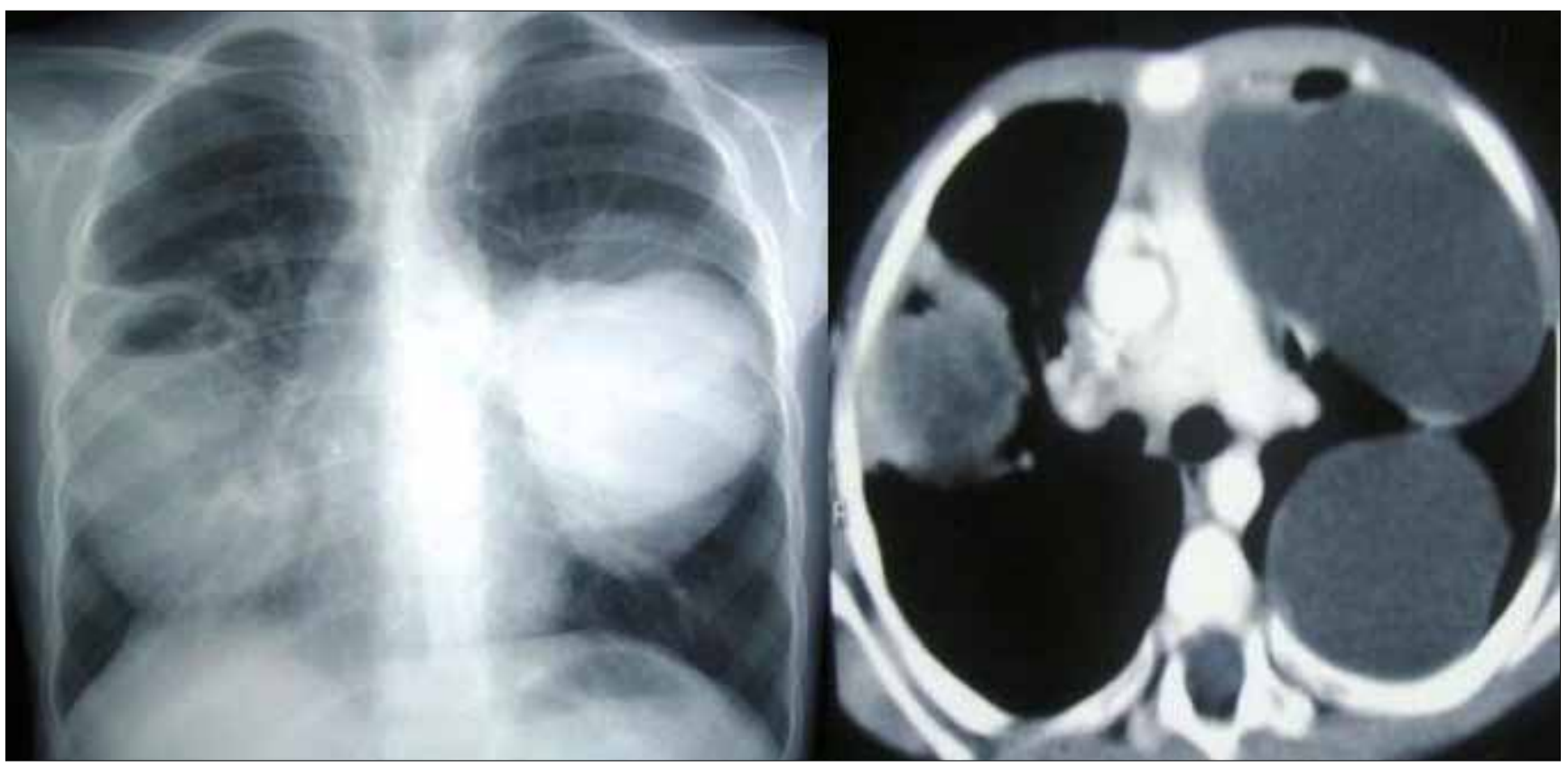

Resim 3. Dört yaşında kız çocuğu. Solda iki adet düzgün sınırlı, intakt, sağda hava sıvı seviyesi gösteren rüptüre kist hidatik 
Hidatik kist cerrahisinde enükleasyon, perikistektomi, basit perikistotomi ve kistik membranın ekstraksiyonu gibi parankim koruyucu yöntemler kullanılmaktadır. Cerrahi yaklaşım ne olursa olsun kist içeriğinin çevreye yayılmaması oldukça önem taşır. Akciğer parankiminin ve çevre dokuların batikon emdirilmiş kompresler ile sarılması, disseminasyonu engellemek için etkili bir yöntemdir. Tüm kistik yapı enükle edilir veya kistik sıvı aspire edildikten sonra membran tamamen çıkarılır ve kavite salin solüsyonu veya dilüe batikon ile yıkanır. Daha sonra geniş bronşiyal açıklıklar kapatıı ve kavite, en dip noktasından yüzeye doğru ayrı ayrı atılan pursestring dikişler ile oblitere edilir (kapitonaj). Pek çok otör, kapitonaj tekniğinin uzamış hava kaçağını engellemek, kaviteyi enfeksiyon ve abse formasyonundan korumak için en güvenilir yöntem olduğunu kabul etmektedir (2325). Ancak, kapitonajın postoperatif sonuçlar açısından herhangi bir farklılık yaratmadığını öne süren ve sadece kavite içindeki bronşiyal açıklıkların sütüre edilmesinin yeterli olduğunu savunan çalışmalar da bulunmaktadır $(26,27)$. Bu konudaki yaklaşım tamamen cerrahın deneyimine ve inisiyatifine bağlıdır.

Bilateral hidatik kistler bilateral torakotomi veya median sternotomi ile yapılan bir veya iki basamaklı cerrahi yaklaşımla tedavi edilir. Komplike olmamış, bilateral hidatik hastalığın tedavisinde bilateral torakotomi uygulanacak ise öncelikle daha büyük olan veya daha fazla sayıda kistin bulunduğu taraf tedavi edilir. Eğer bir taraftaki kist rüptürü olmuş diğer taraftaki intakt ise, rüptüre olmuş kist aciliyet arz etmedikçe, öncelikle intakt kist tedavi edilmelidir. Seçilmiş olgularda torakofrenotomi aracılığıyla, hem akciğer hem de karaciğer kistlerine aynı seansta müdahale edilebilir $(28,29)$. Son zamanlarda cerrahi yaklaşım olarak video yardımlı torakoskopik cerrahi kullanımı bildirilmişse de, bu prosedürün geniş çaplı kabul görmesi için uzun dönem sonuçlarını beklemek gerekecektir (30).
Birçok yayında postoperative komplikasyon oranı \%10-25 arasında bildirilmiştir (17-20). En yaygın problem postoperatif hava kaçağıdır. İntratorasik hematom gibi komplikasyonlar hariç komplikasyonların hemen tamamı konservatif yöntemler ile düzelen minör komplikasyonlardır. Cerrahi sonrası nüks $\% 0-5$ olguda görülür $(17,20,22)$.

Bazı otörler oral mebendazol veya albendazol tedavisinin akciğer hidatik kisti için etkili bir tedavi yöntemi olduğunu düşünmektedir $(31,32)$. Yapılan çalışmalar pulmoner hidatik hastalığı olan hastaların yaklaşık \%70'inin, medikal tedaviye belli oranda yanıt verdiğini göstermektedir $(32,33)$. Ancak antihelmintik tedavi kist membranında degeneratif değişikliklere neden olarak kist rüptürü ve komplikasyon gelişme olasııı̆ını arttııır. Eğer kist rüptüre olup tamamen ekspectore edilirse tam bir tedaviden söz edilebilir. Ne var ki; medikal tedavi ile parazit ölse dahi, kist membranı genellikle kavite içinde kalır ve karaciğer dokusundaki gibi aseptik bir ortam bulunmadığı için sıklıkla sekonder bakteriyel enfeksiyon ve diğer komplikasyonlar gelişir. Antihelmintik tedavi sonrası kist rüptürü en sık 10 gün ile 2 ay arasında gelişmektedir $(32,34)$. Bu nedenle gelişebilecek anaflaktik reaksiyon, asfiksi, tansiyon pnömotoraks, masif hemoptizi gibi ciddi komplikasyonlar açısından medikal tedavi verilen hastalar en az 2 ay yakın gözlem altında olmalıdır. Medikal tedavi kararı verilirken, hastaların büyük çoğunluğunun acil tıbbi müdahale yapılabilecek merkezlerin uzağında kırsal bölgelerde ikamet ettiği göz önünde tutulmalıdır. Ayrıca komplike hidatik kist olgularında daha radikal cerrahi girişimler gerekebileceği, postoperatif morbiditenin daha yüksek, hastane yatış süresinin daha uzun olduğu da unutulmamalıdır $(9,19)$. Günümüzde pekçok uzman medikal tedaviyi yalnızca cerrahiyi tolere edemeyecek hastalarda ve nüksleri engellemek amacıyla kullanmaktadır.

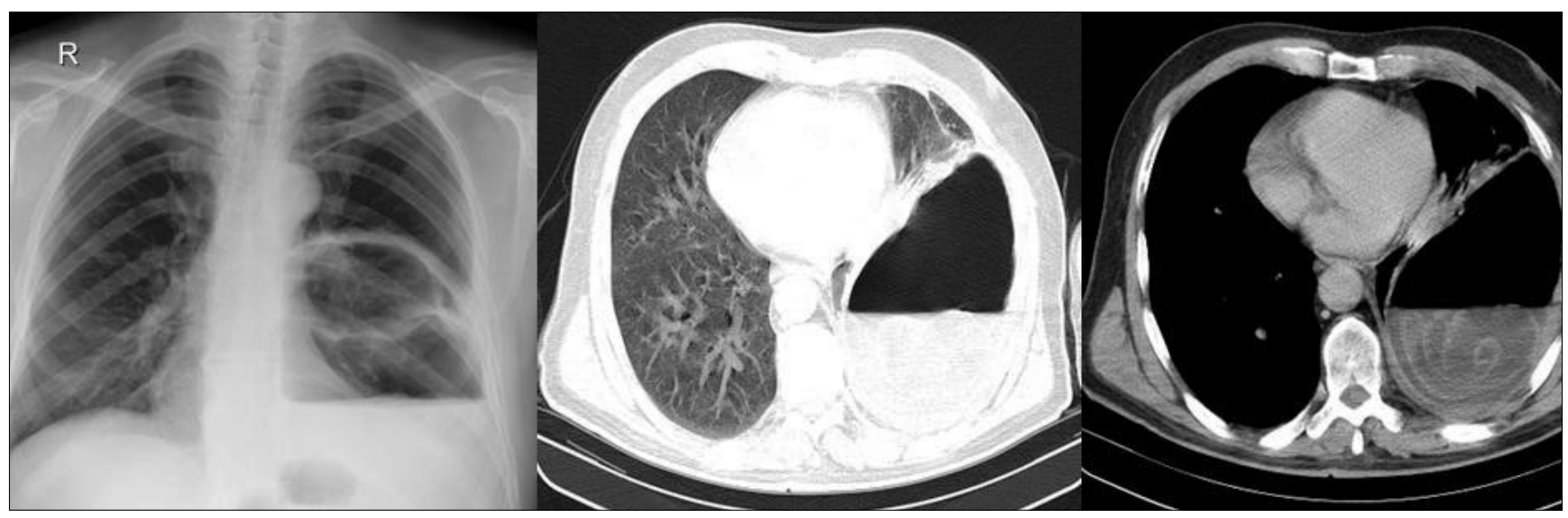

Resim 4. PA akciğer grafide hava-sıvı dansitesi görülen kistik lezyon. Aynı hastanın tomografisinde sıvı içerisinde spiral tarzda kıvrılma gösteren kist membranı görülüyor (spin- whirl sign) 


\section{SONUÇ}

Hidatik kist bölgemizde yaygın olarak görülen bir hastalıktır. Parazitin yaşam siklusunun kırılması hastalıktan korunmada en önemli basamağı oluşturur. Pulmoner hidatik kistler genellikle radyolojik yöntemler ile kolaylıkla tanınabilir. Primer tedavi, pediyatrik yaş grubunda da, erişkin yaş grubunda olduğu gibi cerrahidir. Cerrahi tedavide, mümkün olduğunca, parankim koruyucu cerrahi prosedürler uygulanmalı ve geniş akciğer rezeksiyonundan kaçınılmalıdır. Medikal tedavi profilaksi amaçlı olarak cerrahi ile kombine edilebilir.

\section{KAYNAKLAR}

1. Morar R, Feldman C. Pulmonary echinococcosis. Eur Respir J 2003;21:1069-77. [CrossRef]

2. Romig T. Epidemiology of echinococcosis. Langenbecks Arch Surg 2003;388:209-17. [CrossRef]

3. Gottstein B, Reichen J. Hydatid lung disease (echinococcosis/hydatidosis). Clin Chest Med 2002;23:397-408. [CrossRef]

4. Eckert J, Deplazes P. Biological, epidemiological and clinical aspects of echinococcosis, a zoonosis of increasing concern. Clin Microbiol Rev 2004;17:107-35. [CrossRef]

5. McManus DP, Zhang W, Li J, Bartley P. Echinococcosis. Lancet 2003;362:1295-304. [CrossRef]

6. Sayek I. Kist Hidatik Hastalığı: Klinik Yönleri. Echinococcosis. Altıntaş N, Tınar R, Çoker A. (Editörler). Hidatiloji Derneği Yayınları, İzmir 2004:141-7.

7. Kocer B, Gulbahar G, Han S, et al. An analysis of clinical features of pulmonary giant hydatid cyst in adult population. Am J Surg 2009;197:177-81. [CrossRef]

8. Arroud M, Afifi MA, El Ghazi K, et al. Lung hydatic cysts in children: comparison study between giant and non-giant cysts. Pediatr Surg Int 2009;25:37-40. [CrossRef]

9. Kuzucu A, Soysal O, Ozgel M, Yologlu S. Complicated hydatid cysts of the lung: clinical and therapeutic issues. Ann Thorac Surg 2004;77:1200-4. [CrossRef]

10. Martinez S, Restrepo CS, Carrillo JA, et al. Thoracic maniestations of tropical parasitic infections: a pictorial review. Radiographics 2005;25:135-55. [CrossRef]

11. Tshibwabwa ET, Richenberg JL, Aziz ZA. Lung radiology in the trophics. Clin Chest Med 2002;23:309-28. [CrossRef]

12. Erdem CZ, Erdem LO. Radiological characteristics of pulmonary hydatid disease in children: less common radiological appearances. Eur J Radiol 2003;45:123-8. [CrossRef]

13. Sakamoto T, Gutierrez C. Pulmonary complications of cystic echinococcosis in children in Uruguay. Pathol Int 2005;55:497-503. [CrossRef]

14. Kavukcu S, Kilic D, Tokat AO, et al. Parenchyma-preserving surgery in the management of pulmonary hydatid cysts. J Invest Surg 2006;19:61-8. [CrossRef]

15. Bagheri R, Haghi SZ, Amini M, et al. Pulmonary hydatid cyst: analysis of 1024 cases. Gen Thorac Cardiovasc Surg 2011;59:105-9. [CrossRef]
16. Özçelik C, Inci i, Toprak M, et al. Surgical treatment of pulmonary hydatidosisin children: Experience in 92 patients. J Pediatr Surg 1994;29:392-5. [CrossRef]

17. Dincer SI, Demir A, Sayar A, et al. Surgical treatment of pulmonary hydatid disease: a comparison of children and adults. J Pediatr Surg 2006;41:1230-6. [CrossRef]

18. Kurkcuoglu IC, Eroglu A, Karaoglanoglu N, et al. Surgical approach of pulmonary hydatidosis in childhood. Int $\mathrm{J}$ Clin Pract 2005;59:168-72. [CrossRef]

19. Balci AE, Eren N, Eren S, Ulku R. Ruptured hydatid cysts of the lung in children: Clinical review and results of surgery. Ann Thorac Surg 2002;74:889-92. [CrossRef]

20. Kanat F, Turk E, Arıbas OK. Comparison of pulmonary hydatid cysts in children and adults. ANZ J Surg 2004;74:885-9. [CrossRef]

21. Celik M, Senol C, Keles M, et al. Surgical treatment of pulmonary hydatid disease in children: report of 122 cases. J Pediatr Surg 2000;35:1710-3. [CrossRef]

22. Cangir AK, Şahin E, Enön S, et al. Surgical treatment of pulmonary hydatid cysts in children. J Pediatr Surg 2001;36:917-20. [CrossRef]

23. Kosar A, Orki A, Haciibrahimoglu G, et al. Effect of capitonnage and cystotomy on outcome of childhood pulmonary hydatid cysts. J Thorac Cardiovasc Surg 2006;132:560-4. [CrossRef]

24. Bilgin M, Oguzkaya F, Akcali Y. Is capitonnage unnecessary in the surgery of intact pulmonary hydatid cyst? ANZ J Surg 2004;74:40-2. [CrossRef]

25. Nabi MS, Waseem T, Tarif N, Chima KK. Pulmonary hydatid disease: Is capitonnage mandatory following cystotomy? Int J Surg 2010;8:373-6. [CrossRef]

26. Erdogan A, Ayten A, Demircan A. Methods of surgical therapy in pulmonary hydatid disease: Is capitonnage advantageous. ANZ J Surg 2005;75:992-6. [CrossRef]

27. Turna A, Yılmaz MA, Haciibrahimoglu G, et al. Surgical treatment of pulmonary hydatid cysts: Is capitonnage necessary? Ann Thorac Surg 2002;74:191-5. [CrossRef]

28. Şahin E, Enön S, Cangır AK, et al. Single-stage transthoracic approach or right lung and liver hydatid disease. J Thorac Cardiovasc Surg 2003;126:769-73. [CrossRef]

29. Kurul IC, Topcu S, Altinok T, et al. One-stage operation for hydatid disease of lung and liver: principles of treatment. $J$ Thorac Cardiovasc Surg 2002;124:1212-5. [CrossRef]

30. Parelkar SV, Gupta RK, Shah H, et al. Experience with videoassisted thoracoscopic removal of pulmonary hydatid cysts in children. J Pediatr Surg 2009;44:836-41. [CrossRef]

31. Keshmiri M, Baharvahdat $\mathrm{H}$, Fattahi $\mathrm{SH}$, et al. A placebo controlled study of albendazole in the treatment of pulmonary echinococcosis. Eur Respir J 1999;14:503-7. [CrossRef]

32. Keramidas D, Mavridis G, Soutis M, Passalidis A. Medical treatment of pulmonary hydatidosis: complications and surgical management. Pediatr Surg Int 2004;19:774-6. [CrossRef]

33. Doğru D, Kiper N, Ozçelik U, et al. Medical treatment of pulmonary hydatid disease: for which child? Parasitol Int 2005;54:135-8. [CrossRef]

34. Todorov T, Vutova K, Donev S, et al. The types and timing of the degenerative changes seen in the cysts during and after benzimidazole treatment of cystic echinococcosis. Ann Trop Med Parasitol 2005;99:649-59. [CrossRef] 